\title{
Post-Formal Thought in Gerontagogy or beyond Piaget
}

\author{
André Lemieux \\ Department of Education and Pedagogy, University of Quebec at Montreal, Montreal, Canada \\ Email: lemieux.andre@uqam.ca
}

Received May 30, 2012; revised June 25, 2012; accepted July 2, 2012

\begin{abstract}
Jean Piaget, one of the most influential theorists in developmental psychology, assumed that formal thought, characterized by the development of an individual's logical capacities, was the last stage of adult thinking. In this article, we review how the brain evolved, describing its main structures, and examining each cerebral hemisphere's specific functions. Evidence is also provided for the production of new neurons and new connections between them, forcing a revision of old theories about the decline of intellectual functions in the elderly. We then consider Jones' theories X and Y, and the different definitions of intelligence (fluid vs. crystallized, and qualitative vs. quantitative), and how these perspectives have influenced the way we see intelligence. Evidence supporting the addition of another stage, named postformal thought, is examined in the context of gerontagogy. Dialectical thought characterizes this stage, and developing wisdom is its main goal. We examine the two basic principles of dialectical thought, namely the principle of contradiction and the principle of relativity of everything. It is suggested that the learning of wisdom should be the focus of future university programs to educate the elderly.
\end{abstract}

Keywords: Gerontagogy; Educational Gerontology; Elderly; Post-Formal Thought; Theory X; Theory Y; Qualitative Intelligence; Quantitative Intelligence; Piaget; Dialectical Thought; Wisdom

\section{Introduction}

Piaget sees in the associative tradition an overly exclusive mechanistic nature and in the Gestalt tradition, an overly exclusive nativist aspect. He tries to explain how knowledge accumulates through a fresh questioning of existing relationships between biological structures and cognitive structures; he thus finds himself halfway between these two poles. His research is deemed epidemiological because it critically analyzes fundamental processes in knowledge acquisition. It is also deemed genetic because it attempts to demonstrate the progressive development of intelligence through descriptions of the ways in which cognitive structures emerge [1].

Jean Piaget's genetic epistemology is still one of the predominant theories in contemporary psychology. Yet, we must ask ourselves whether intellectual development ends with the development of an individual's logical abilities. From this perspective, according to Cohen, we can "hope to elaborate an exhaustive theory on psychological evolution (as) ... still according to him, theories that emphasize learning hold little interest” [2].

"If Piaget's assertion that formal thought constitutes the crowning achievement of human ontogeny is accepted ... a pessimistic view of adulthood becomes a logical necessity" [3]. "Neuroscientists have clearly shown that... Brain scans of adolescents show they are far from ma- turity and that they experience major structural changes well beyond puberty" [4]. Yet, in our paper, we will see that our brain is triune and, contrary to popular belief, does not lose its flexibility with age. It is capable of learning throughout the life-span. However, with theories $\mathrm{X}$ and $\mathrm{Y}$, Jones shows how we came to believe in the decline of intelligence. Then, we discuss the theory of quantitative and qualitative intelligence. We define qualitative intelligence and examine styles of fluid and crystallized thinking. Last, we consider post-formal thinking, which allows intellectual thought to continue developing in old age, even beyond formal thinking.

In conclusion, we will see that the development of learning in the elderly person is not only possible but also essential and beneficial to maintain efficient cognitive functions throughout the life-span. "At the age when strength decreases, we cease to train people despite their desire to continue to take care of themselves ... Education that ceases at a certain age fails in its fundamental goals" [5].

\section{Evolutionary Perspective of the Brain}

Many elders withdraw from society because they are left with isolation as the only possibility. However, in the future, society will allow seniors to develop a "joie de vivre" and a sense of accomplishment. This will become 
possible to the extent that society acknowledges that the elderly person is not inevitably headed towards senility but is rather as capable of intellectual activity as other members of society.

Already in 1991, MacLean observed that:

"Some pundits would claim that in the past, when there was a relatively short life expectancy, we were victimized by young people who believed they had to do or die before the age of forty or fifty. Hence, with current life expectancy, if aging might bring the learning experience and wisdom for more meaningful survival of humanity and the rest of earthly life, there would exist an urgent need to proceed with all haste to learn how the brain could better protect itself and cleanse itself of injurious substances. Such knowledge might prove to be a crucial next step in evolution [6]".

Nonetheless, for more than a century, psychology has given little or no consideration to the evolutionary perspective on brain development. Yet, psychology has biology as a substratum and it is based on evolutionary theory. Consequently, psychology is said to consider the evolution of the human mind as the adaptive phenomenon of problem solving for problems encountered by the first human beings. Psychology uses this concept of the "Environment of Evolutionary Adaptedness (EAA)" [7] in an effort to explain the evolution of the general mechanisms behind human intelligence and learning. MacLean is the most original of the advocates of this evolutionary psychology which questions the standard social science model of the nature of the mind.

\subsection{The Triune Brain}

Paul MacLean [8] suggests one of the most fascinating tools for understanding the brain. He alleges that the shape of the brain can only be understood through the human evolutionary theory that brought it to life. He presents the most holistic way to conceive of the brain structure in relation to its historical evolution in describing the brain as "triune", comprised of three distinct brains corresponding to three evolutionary phases that the human race has undergone throughout its history, notably.

\subsubsection{A “Reptilian” Brain}

A "reptilian" brain (developed two hundred million years ago), the most ancient, which ensures the organism's vital functions by controlling the heart rate, breathing, body temperature, balance, etc. It includes the brainstem and the cerebellum, the essential components of a reptile's brain. It is reliable but it tends to be rather rigid and compulsive. We thus find in this neuro-vegetative center the primary functions, as well as the instinctual Freudian id in its entirety.

\subsubsection{A "Limbic" Brain}

A "limbic" brain (developed one hundred million years ago) that appeared with the first mammals, capable of remembering pleasant or unpleasant behaviours, which in turn is responsible for what we call emotions. It is primarily comprised of the hippocampus, the amygdala, and the hypothalamus. It is the seat of our often unconscious value judgments, which exert an important influence on our behaviour. In this brain, we find an acquired superior instructive-emotional set, the adaptor and modulator of the reptilian brain's instinct. This would be where the Freudian ego lies.

\subsubsection{A "Neocortex"}

A "neocortex" (developed half a million years ago), which gained importance in primates and culminated in humans with two large cerebral hemispheres, which have become increasingly critical. It is because of these hemispheres that language, abstract thought, imagination, and conscience were able to develop. The neocortex is flexible and has quasi-infinite learning capacities. It is also because of the neocortex that humans conceptualize culture. This layer developed in the hominid branch from which human beings appeared. The neocortex plays a very important role in humans' reflective intellectual and emotional activities. It is in this part of the brain that we could locate, if necessary, the Freudian superego. This neocortex is the part of the brain whose functioning neurosurgeons understand the best, as it is the easiest part of the brain's anatomy to access, both surgically and experimentally.

Yet, these three brain structures do not function independently and they have created numerous connections through which they can influence each other. For example, the nervous pathways from the limbic system to the cortex are particularly developed. The cerebral structures' co-evolution in mammals is worth exploring.

\subsection{The Neocortex's Two Hemispheres}

From a histological perspective, the human brain is comprised of two hemispheres. One of the main characteristics of these two hemispheres is their antagonism. Each is specialized in its own thinking style and has faculties that are peculiar to it. "Today, we have tremendous evidence attesting that the human brain has become specialized and that each of this organ's two halves is responsible for a thinking style that is quite distinct [9].”

\subsubsection{The Left Hemisphere}

The left hemisphere of the brain is associated with logic, language, and analytical thinking. It excels when it 
comes to naming and categorizing things, as well as in everything regarding symbolic abstraction, speech, reading, writing, and arithmetic. The thinking style is linear; everything is placed sequentially following a given order. This thinking style is typically developed through education, with an emphasis on literature and mathematics. The left hemisphere controls the right part of the body. "Many experiments on normal subjects would also suggest that the left hemisphere is the main agent for everything concerning language development [10].”

\subsubsection{The Right Hemisphere}

As for the right hemisphere, it functions in an integrative manner and excels at everything that is visual, spatial, perceptual and intuitive. The thinking style is non-linear and non-sequential, and processing is very fast. The right hemisphere analyzes things comprehensively and determines the spatial relations between diverse parts of a whole very quickly. This part of the brain does not deal with sorting things into diverse categories pre-established by laws. On the contrary, it seems to indulge in complexity, ambiguity, and paradoxes. As such, it is difficult to describe this thinking style due to its complexity, its rapid processing of information and its non-verbal nature. The right hemisphere of the brain is associated with creativity.

"Some researchers believe the primary and secondary thinking processes belong to different brain hemispheres, that is that the right hemisphere is responsible for primary creative thought, whereas the left hemisphere controls logical secondary reasoning [11].”

The hemispheres are interconnected by nervous cells called neurons, which form an extremely complex network. At birth, the brain has billions of neurons that have developed at a rate of 250,000 every second during the embryonic stage of the human fetus. However, beginning at age 25, the number of neurons decreases considerably, at the rate of 100,000 every day. Not so long ago, it was believed that neurons did not multiply and disappeared forever despite the fact that R. Santiago y Cajal [12] had already demonstrated that glial cells had the capacity to reproduce through mitosis alone. Yet, recent research on neural plasticity [13] and the findings of Professor Lledo's team at the Pasteur Institute and at the CRNS in Paris [14] unequivocally conclude that neurons in the human brain can multiply.

Better still, the production of new neurons shows the human brain's capacity for self-repair. Yet, even in old age, new neurons emerge in certain brain areas. Using these newly formed neurons, it might be possible to discover new approaches to treating neurodegenerative diseases such as Parkinson's disease.

Yet, one of the main factors preventing the development of educational programs in gerontagogy is the be- lief that the elderly are unable to acquire significant learning because of their neurons' considerable decline. Science refutes this myth and forces us to rethink theories on intellectual ageing.

\section{Intelligence and Brain}

\subsection{Jones' Theories $X$ and $Y$}

Sidney Jones [15] was one of the first researchers to challenge the belief that the elderly are unable to learn following the decline of their intellectual capacities. He analyzed different perspectives on the physical degeneration of the brain in ageing in an article published by the Beth Johnson Foundation Publications of Great Britain, following a Keele University conference on the liberation of the elderly which brought together leading British researchers.

\subsubsection{Theory $X$}

This theory presents one of the most pessimistic degenerative views of intellectual capacities and their effects on learning for the elderly.

"According to received wisdom the physiological substrates of these psychological phenomena are principally: the progressive loss of brain cells throughout our lives, a loss which is irreplaceable; and the degeneration of the cells which are retained. This commonly conceived syndrome of creeping and irreversible decline in intellectual capacity, a decline based on physiological loss and degeneration might be termed theory $X$ [15]."

From this perspective, an individual's ageing brings a decrease in all physical and psychological capacities. Theory $\mathrm{X}$ gives us a pessimistic and purportedly definitive view of ageing. This theory shows that in the first years of life, there is a growth of our physical and intellectual capacities, followed in the last years by the decline of those same capacities. It is inexorable.

This fatalistic theory has a pernicious effect on individuals and society. Indeed, expectations of the elderly's capacities are not very high. This theory leads to seniors' loss of motivation to change and to their acceptance of their decrepitude as inevitable. Accepting this theory is so pernicious and harmful that Jones presents theory $\mathrm{Y}$ to balance theory $\mathrm{X}$.

\subsubsection{Theory $Y$}

According to Jones, theory $\mathrm{X}$ should be called into question and we should find a theory better adapted to the reality of ageing. This theory, which he calls theory Y, claims that the loss of brain cells is not as significant as suggested by theory $\mathrm{X}$, so that intellectual functions remain roughly stable until old age. However, he points out that researchers do not all agree on the question of cell loss. 
"Rose (1971) asserts that by the age of seventy years we will have lost $2(1 / 2) \%$ of the total. This is very slight in comparison with estimates of loss made by others, notably Woodburne (1976) who believes that nearly a quarter of the neurons have been lost in the same period [15]."

When we consider that at birth, a human being has 10 to 12 billion cells with the capacity to establish over 10,000 synaptic connections with each of its neighbors and then, when we take into account the fact that we use only $15 \%$ of our brain capacity, we have to realize that theory $\mathrm{X}$ must be put into perspective and applied with great caution.

Similarly, Schwartz [16] claims that Lashley's hypothesis, according to which there exist an impressive number of neurons in the cerebral cortex, allows us to question theory X. With these two arguments, Jones concludes:

"The probability that the learning function involves the whole brain, and the fact that we appear to have large reserves of cortical capacity capable of sustaining large losses of neurons, are factors which taken together create serious questions for theory $X$ [15]."

Jones states that two additional arguments strengthen theory Y. The first is related to society's negative attitudes towards the elderly person and the second to the elderly's lack of intellectual exercise. The first hypothesis assumes that social stereotypes have an influence on motivation, self-concept, the environment, education, and even some intellectual operations such as the sorting of information, logical deductions, or complex abilities such as creativity [17]. Society's negative images concerning ageing certainly have a deleterious effect, not only on the elderly person's self-concept, but also on the elderly's poor results on intelligence, memory, and perceptual ability tests. "To avoid having seniors ceasing to learn ... Society must also ensure that the elderly are not abruptly deprived of their social role [4]."

The second argument puts forward the hypothesis that exercise plays a crucial role in maintaining intellectual functions. "Intellectual functions decline when we stop using them. The concept of learning throughout the life-span thus seems beneficial [4]."

This assertion is based on two observations:

The first assumes that elders with a high level of education have better short-term memory than less educated elders. In addition, the latter have poorer health and a poorer self-image than the former. "The adults of today have a level of education superior to that of previous generations. It can be said that we have strong evidence for the decline with age ... of long-term memory ... [4]"

The second observation [18-20] is based on the fact that an elder's verbal capacity remains stable, whereas the other intellectual functions decline somewhat with age.

The reason why verbal capacity remains stable is that we are forced to use this capacity everyday. This is why the daily use of speech leads us to believe that perceptual abilities, intelligence, memory, creativity, and learning capacity could remain stable and even increase if they were used in a sustained fashion.

As we see it, intellectual activity is as important as physical activity to maintain good mental and physical health [21]. Verghese's research strengthens theory Y, which suggests that an individual's intellectual capacities are maintained by consistent use and atrophy with lack of use.

In conclusion, theory $\mathrm{Y}$, which asserts that the elderly's intellectual capacities remain stable throughout their life-span, is as valid as theory $\mathrm{X}$, which claims that intellectual capacities disappear with age. In fact, it is not age itself that brings a decline in intellectual capacities, but the lack of exercise due to the lack of possibilities for elderly people to exercise their intellectual faculties. From this perspective, nothing prevents the elderly from developing their intellectual capacities throughout their lives.

With theories $\mathrm{X}$ and $\mathrm{Y}$, we see that researchers do not agree on the decline of intelligence in seniors because they do not define intelligence the same way. Indeed, research shows that intelligence can be defined from a quantitative or qualitative perspective, which we will present as quantitative or qualitative intelligence.

\subsection{Definitions of Intelligence}

\subsubsection{Quantitative Intelligence}

Indeed, in theory $\mathrm{X}$, researchers assume that all aspects of intelligence that increase eventually decrease. With the "Weschler's Adult Intelligence Scale (WAIS)" test, Weschler [22] demonstrated that old people are less intelligent than young people and that intelligence increases until age 30, remains stable for 10 years, and begins to decline around 40 years old. Miles and Miles [23] and Jones and Conrad [24] confirmed this hypothesis by showing that seniors obtain poorer results when they are subjected to intelligence tests that require completing a task in the shortest time possible.

While improving intelligence tests allowed for better interpretation of results, it did not allow us to address the problem that not only there was no agreement on a common measure, but also again that intelligence was defined differently. According to this school of thought, the definition of intelligence is summarized as the capacity to do well on an intelligence test [25]. It is presented as a quantitative entity, thus measurable. "Tests have transformed the notion ... of intelligence: ... it has become a unique quantifiable entity [26]." 


\subsubsection{Qualitative Intelligence}

Yet, many researchers who criticized the tests' statistical methods wanted to present intelligence as multifaceted and qualitative rather than a unique and quantifiable entity.

The distinctive contribution of Terman [27] at the inception of this new orientation in the definition of intelligence, is presenting intelligence as the capacity to learn, to reason, to elaborate concepts, and to play with abstractions. Botwinick [28] sees intelligence as multidimensional and Horn [29] distinguishes two dimensions, fluid intelligence and crystallized intelligence. Baltes and Shaie [30] and Willis and Baltes [31] present fluid intelligence as being comprised of faculties that are independent of culture, whereas we find in crystallized intelligence the aptitudes acquired through education and culture. This type of intelligence is characterized by plasticity, allowing individuals to assimilate their own culture's collective intelligence.

\section{Qualitative Intelligence and Basic Forms of Dialectical or Post-Formal Thought}

\subsection{Elementary Forms of Piaget's Dialectical Thought}

Piaget [32] portrays qualitative intelligence as the capacity to adapt to one's environment. Piaget [33] presents this plasticity as being rooted in a dialectical conceptualization of intelligence, which characterizes the elder's thinking style.

The reader will be surprised by our comments on Piaget's genetic epistemology and Marx's dialectical theory. Indeed, "Seldom has genetic epistemology been considered as a dialectic of knowledge. Piaget's own references to this aspect of his theory are scattered and indirect [34]."

Moreover, numerous critics claim that Piaget cannot be assimilated into a Marxist tradition and that genetic epistemology cannot be compared to Marxism as it handles this philosophy in a completely different way.

Yet, this definition of dialectic proposed by Piaget. "There is dialectic when two systems, thus far distinct and separated but not at all opposed to each other, merge into a new whole, the properties of which surpass the originals, and sometimes by a considerable extent," [34] is eerily similar, according to Garcia, "to the characterization of dialectic as a theory of is eerily similar, according to Garcia, "to the characterization of dialectic as a theory of opposites." opposites." The word opposites, he adds, should not be interpreted "in the exact sense of formal logical contradiction."

In addition, Piaget's definition of dialectic assumes that the two independent systems, which appear as absolutes and give birth to a new whole, must undergo a "re- vitalization" process to build a larger system than the previous two. Thus, in Piaget's definition, we have the two principles that constitute a dialectical thought, namely the principle of contradiction and the principle of revitalization of everything. However, it must not be presumed that dialectic intervenes at every step of cognitive development. In the analysis of logical-mathematical thought, it seems:

"Once a theory has been established, it operates in a purely deductive (or 'discursive') manner. And deduction as such is not dialectical [34]".

This is why scientists are reluctant to include dialectic in scientific theories but prefer to function in a deductive manner in their "problem solving."

Formal or dialectical thought

Consequently, it seems possible to claim that:

"Piaget belongs-whether he likes it or not-to a line of thought ... of the most important dialectical school of our time. [Hegel, Marx and Lenin] ... Genetic epistemology has created (or has begun to create) the psychogenetic and sociogenetic research program that Lenin pointed out as being necessary ... [34]"

\subsection{Choice of Formal Thought in the Work of Piaget}

However, we must admit that, although Piaget presents basic forms of dialectical thought in the child's cognitive development, researchers agree that his work focuses mainly on the development of logical-mathematical or formal thought. We have to wait until John M. Rybash's writings, which synthesize the literature on the essence of post-formal thought, namely dialectical thought, to understand that although it is found in young people, it is above all the prerogative of elders. Genetic epistemological research shows that older people's thinking style is qualitatively different from the characteristics of Piaget's formal operations. Those thinking styles that we only find in seniors are post-formal in nature. In the next section of our article, we will introduce the characteristics of this post-formal thought.

\section{Qualitative Intelligence and Rybash's Fundamental Principles of Dialectical or Post-Formal Thought}

Although Rybash was able to present a synthesis of adult thought in a single volume, we must acknowledge that Basseches [35-37] was the foremost scholar in the area of dialectical thought.

He is the one who published the most research in this field and who emphasized the four aspects of post-formal thought. Indeed, his research led him to demonstrate that post-formal thought is based on:

a) The contradiction and relativity of knowledge; 
b) The development of meta-systemic reasoning or reflective thought;

c) The "problem finding" rather than "problem solving";

d) The development of dialectical thought.

In the following portion of the text, we will examine each of the points listed above to explain their originality.

\subsection{Contradiction and Relativity of Knowledge}

The principles of contradiction and relativity are notions that were originally brought to us by Marx and Einstein. With his principle of contradiction, Marx has familiarized us with the idea that an antithesis opposed every thesis, which together formed a synthesis, that is to say a new reality coming from the thesis and the antithesis, but which had nothing to do with these items anymore. This position, applicable by Marx in sociology, brought deep instability as change was any reality's dynamic element and nothing could be taken for granted. We have already developed this Marxist principle in our analysis of Piaget's thoughts.

Yet, when we apply this principle of contradiction to our development of knowledge, we are forced to acknowledge the: “... necessary subjectivity to describe relativistic thinking within the area of the interpersonal relations. Necessary subjectivity means that interpersonal reality is characterized by mutually contradictory frames of reference [38].”

In that context, researchers discover that the reciprocal contradiction of frames of reference brings a kind of knowledge asymmetry or imbalance that no observer is able to properly explain. "It was the detection of a type of asymmetry that compelled Einstein toward the development of his theory of relativity [39]."

As we have just shown, this contradictory and relativistic nature of post-formal thought applies not only to pure sciences such as physics but also to social sciences like psychology.

\subsection{Meta-Systemic Reasoning}

We must conclude that this type of thinking brings us to a reasoning that is other than logical, a meta-systemic reasoning, typical of reflective thought. This reasoning does not imply knowledge of a system's elements, but knowledge of operations that apply to different systems, thus, that goes beyond the systems to observe their interactions. This ability to create meta-systemic operations endows people with the logical capacity to understand the legitimacy of value systems other than their own. These qualitative adaptations in adult thought are related to meta-ethical changes that emerge at this stage of life. Kohlberg [40] provides a convincing example of this in his longitudinal analysis of moral reasoning from adolescence to adulthood.

\subsection{Problem Finding}

Arlin [41] compared the characteristics of Piaget's formal thought with the characteristics of post-formal thought that we just covered. Her analysis shows that formal thought, the thought associated with formal operations, is mainly related to problem solving from a logical perspective that evolves in a known system, the interrelations of which we can control. However, her study shows that post-formal thought is essentially related to solving tasks, linked to presenting a problem within its context and in all of its dimensions (problem finding).

Yet, in her study, Arlin asserts that, for problem finding, a person must be capable of problem solving. As a result, formal thought or the capacity to develop Piaget's formal operations is a necessary prerequisite to access post-formal thought or the capacity to create post-formal operations, that is vast intellectual operations on the principles of the contradiction and relativity of everything. This is why she suggests adding a fifth post-formal stage to Piaget's four stages.

\subsection{Development of Dialectical or Post-Formal Thought}

In the previous paragraphs, we saw that post-formal thought functions through operations based on the principles of contradiction and relativity, whereas formal thought functions through logical-mathematical operations. While formal thought is termed logical thought in Piaget's theory, Rybash [42] uses the term dialectical for post-formal thought. Many researchers, such as Sinnott and Guttman [43] Basseches [35-37] and Kramer and Woodruff [44] have studied the development of dialectical thinking in adulthood. Even though these researchers used different conceptual and methodological approaches to study dialectical thought, they all conclude that this thinking style falls within the constructivist tradition, meaning that operations are created by individuals and are not mere copies of reality.

Moshman [45] has been the one who most insisted on the constructivist nature of all knowledge. He argues that Piaget's theory and Piaget's own thinking fall within a dialectical constructivist thinking paradigm. From that perspective, Moshman's work analyzes the assertions we expressed earlier in the paragraph on Piaget's basic forms of dialectic in depth.

Although dialectical thinking operates differently from formal thinking, we hypothesize that there exists, after the formal thinking stage, a fifth stage of post-formal thinking, as Piaget had already studied its basic forms and would have concluded the same thing, had he had time to do so. However, we cannot credit Piaget with this notion, as we are simply hypothesizing. We can only 
state that post-formal thought constitutes a thinking style peculiar to adult thinking.

\section{Conclusions}

In this article, we have demonstrated that the human brain has an infinite regenerative capacity and that even if we lose brain cells with age, the brain compensates for this loss and creates other synaptic connections that allow it to continue having enriching intellectual activities throughout the life-span.

Based on this observation, with his theories $\mathrm{X}$ and $\mathrm{Y}$, Jones demonstrated that, depending on whether we define intelligence in a quantitative or qualitative manner, we have a pessimistic or an optimistic outlook on the possibility of learning in old age.

While it is true that sensory functions, speed of processing, and long-term memory decline with age, there is evidence that vocabulary, semantic knowledge, and wisdom all increase with age. These cognitive functions are very important in the learning experience of the elderly, as we have shown in describing post-formal thought. Thus, seniors must take advantage of this post-formal thought in confronting the intellectual challenges preventing them from wanting to continue learning throughout their lives, and depriving them of an excellent tool to counter degenerative brain diseases.

Indeed, research shows that intense and consistent intellectual stimulation may prevent or at least limit the decline of cognitive functions. It is now established that every step of our life corresponds to a specific learning experience in our personal development that depends on our biological, psychological, societal, and personal maturity. Thus, for the elderly, with the development of post-formal thinking, the ideal goal of learning is the acquisition of wisdom. "Thus, wisdom is not simply for wise people or curious psychologists; it is for all people and the future of the world [46]."

From that perspective, life experiences and an elder's personality are more important in the functioning of post-formal or dialectical thinking than the pure intellectual logic of formal thinking to acquire wisdom, wisdom being, as mentioned before, the aim of adult learning. Indeed, wisdom makes elders aware of themselves and of their own identity by fostering a comprehensive conception of human development in its limited, intellectual, social, and genetic aspects. "Wisdom, a notion that the university had transformed to science in their theology and philosophy faculties, finally finds its true identity in action, in the education faculties [47]."

While researchers in the education sciences have thus far neglected the aspects we developed in this article, we hope that in the future, it will be possible to develop research in this field in universities. This would allow researchers to further knowledge on the psychology of learning in the elderly to carry out a university program focused on the acquisition of wisdom.

Note: All quotations in italics were originally in French and were translated herein by the authors to make the article easier to read. The authors are the only ones responsible for these translated quotations.

\section{REFERENCES}

[1] F. Y. Doré and P. Mercier, "Foundations of Learning and Cognition,” In: G. Morin, Ed., Les Fondements de L'apprentissage et de la Cognition, Boucherville, Québec, 1992, pp. 65-69.

[2] D. Cohen, “A New Examination of Piaget,” Éditions Retz, Paris, 1981, pp. 11-12.

[3] G. Labouvie-Vief, "Logic and Self-Regulation from Youth to Maturity,” In: M. L. Commons, F. A. Richards and C. Armon, Eds, Beyond Formal Operations: Late Adolescent and Adult Cognitive Development, Praeger, New York, 1984, pp. 158-179.

[4] CERI, "Understanding the Brain: The Birth of a Learning Science,” OCDE, Paris, 2007, pp. 59-61.

[5] A. Lemieux, “Gerontagogy: A New Reality,” Éditions Nouvelles, Montréal, 2001, p. 63.

[6] P. D. MacLean, “Expanding Life-Span Learning,” In: D. Dickinson, Ed., Creating the Future: Perspectives on Educational Change, John Hopkins University, Columbia, 1991, pp. 1-4.

[7] D. Chiappe and K. Macdonald, "The Evolution of Domain-General Mechanisms in Intelligence and Learning," The Journal of General Psychology, Vol. 132, No. 1, 2005, pp. 5-40.

[8] P. D. MacLean and R. Guyot, “The Triune Brain,” Robert Laffont, Paris, 1990.

[9] R. E. Ornstein, "We Think with the Left Brain Hemisphere, We Love with the Right Brain Hemisphere," Psychologie, No. 44, 1973, pp. 27-31.

[10] H. Gardner, "The Left Brain Hemisphere Does Not Understand Jokes,” Le Cerveau Gauche ne Comprend Pas La Plaisanterie, Psychologie, No. 137, 1981, pp. 29-32.

[11] C. Martindale, “Intelligence and Creativity,” Intelligence et créativité, Psychologie, No. 70, 1975, pp. 37-42.

[12] R. S. Y. Cajal, "Texture of the Nervous System of Man and the Vertebrates," Springer-Verlag Wien, New York, 1999. doi:10.1007/978-3-7091-6435-8

[13] M. Ptito, "Eye and Brain in Laboratory," L'œil et Le Cerveau En Observation, Forum, Vol. 36, No. 9, 2001, pp. 115-117.

[14] M. Alonso, I. Ortega-Perez, S. M. Grubbs, J. P. Bourgeois, P. Charneau and P. M. Lledo, “Turning Astrocytes from the Rostral Migratory Stream into Neurons: A Role for the Olfactory Sensory Organ,” Journal of Neuroscience, Vol. 28, 2008, pp. 11089-11102.

[15] S. Jones, "The Abilities of the Elders: Theory $X$ and Theory Y,” Beth Johnson Foundation Publications, London, 1976, pp. 9-29. 
[16] M. Schwartz, "Physiological Psychology," AppletonCentury-Crofts, New York, 1973.

[17] J. E. Jones, “On Teaching Art to the Elderly: Research and Practice,” Educational Gerontology, Vol. 5, No. 1, 1980, pp. 24-25.

[18] R. D. Savage, P. G. Britton, N. Bolton and E. H. Hall, "Intellectual Functioning in the Aged," Methuen and Co. Ltd., London, 1973.

[19] A. Heron and S. Chown, "Age and Function," Hess, Churchill, 1967, pp. 139-146.

[20] E. Harwood and G. F. K. Naylor, "Changes in the Constitution of the WAIS Intelligence Pattern with Advancing Age,” Australian Journal of Psychology, Vol. 23, No. 3, 1971, pp. 297-303.

[21] J. Verghese, R. B. Lipton, M. J. Katz, C. B. Hall, C. A. Derby, G. Kuslansky, A. F. Ambrose, M. Sliwinski and H. Buschke, "Leisure Activities and the Risk of Dementia in the Elderly,” New England Journal of Medecine, Vol. 348, No. 25, 2003, pp. 2508-2516. doi:10.1056/NEJMoa022252

[22] D. Wechsler, "Manual for the Wechsler Adult Intelligence Scale,” Psychological Corporation, New York, 1955.

[23] C. C. Miles and W. R. Miles, "The Correlation of Intelligence Scores and Chronological Age from Early to Later Maturity," American Journal of Psychology, Vol. 44, No. 1, 1932, pp. 44-78. doi:10.2307/1414956

[24] H. E. Jones and H. S. Conrad, "The Growth and Decline of Intelligence: A Study of Homogeneous Population between the Ages of Ten and Sixty," Genetic Psychology Monograph, Vol. 13, 1933, pp. 233-298.

[25] G. E. Boring, "Intelligence as the Tests Test It," New Republic, Washington DC, 1923, pp. 35-37.

[26] O. Martin, "Measure in Psychology from Binet until Thurstone," La Mesure En Psychologie de Binet à Thurstone, Revue de Synthèse, Vol. 118, No. 4, 1997, pp. 457493.

[27] L. M. Terman, “The Measurement of Intelligence,” Houghton Mifflin, Boston, 1916. doi:10.1037/10014-000

[28] J. Botwinick, "Aging and Behavior: A Comprehensive Interaction of Research Findings,” Springer, New York, 1984.

[29] J. L. Horn, "Organization of Data on Life-Span Development of Human Abilities,” In: L. R. Goulet and P. B. Baltes, Eds., Life-Span Development Psychology: Research and Theory, Academic Press, New York, 1970, pp. 423466.

[30] P. B. Baltes and K. W. Shaie, "On the Plasticity of Intelligence in Adulthood and Old Age," American Psychologist, Vol. 31, No. 10, 1976, pp. 720-723. doi:10.1037/0003-066X.31.10.720

[31] S. L. Willis and P. B. Baltes, "Derivation of Geron-toLogical Training Research from Theory of Intelligence: A Reply to Donaldson and Some Critical Observations," Journal of Gerontology, Vol. 36, No. 5, 1981, pp. 634-
638.

[32] J. Piaget, "Adaptation and Intelligence Psychology: Organic Selection and Phenocopy,” Herman, Paris, 1974.

[33] J. Piaget, "Basic Forms of the Dialectic,” Idées/Gallimard, Paris, 1980.

[34] R. Garcia, "Dialectic, Psychogenesis and the History of Sciences,” Idées/Gallimard, Paris, 1980, pp. 229-249.

[35] M. Basseches, "Dialectical Schemata: A Framework for the Empirical Study of Dialectical Thinking," Human Development, Vol. 23, 1980, pp. 400-421. doi:10.1159/000272600

[36] M. Basseches, "Dialectical Thinking as Metasystematic Form of Cognitive Organization,” In: M. L. Commons, F. A. Richards and C. Armon, Eds., Beyond Formal Operations: Late Adolescent and Adult Cognitive Development, Praeger, New York, 1984, pp. 216-238.

[37] M. Basseches, "Dialectical Thinking, an Adult Development,” Ablex, New York, 1984.

[38] J. D. Sinnott, "Postformal Thinking: The Relativistic Stage,” In: M. L. Commons, F. A. Richards and C. Armon, Eds., Beyond Formal Operations: Late Adolescent and Adult Cognitive Development, Praeger, New York, 1984, pp. 298-325.

[39] G. Holton, "Thematic Origins of Scientific Thought: Kepler to Einstein,” Harvard University Press, Cambridge, 1973.

[40] A. Colby, L. Kohlberg, J. Gibbs and M. Lieberman, “A Longitudinal Study of Moral Judgement. Monographs of the Society for Research,” Child Development, Vol. 48, 1983, pp. 1-124.

[41] P. K. Arlin, "Cognitive Development in Adulthood: A Fifth Stage?” Developmental Psychology, Vol. 11, No. 5, 1975, pp. 602-606. doi:10.1037/0012-1649.11.5.602

[42] J. M. Rybash, W. J. Hoyer and P. A. Roodin, “Adult Cognition and Aging: Developmental Changes," In: Processing Knowing and Thinking, Pergamon Press, New York, 1986.

[43] J. D. Sinnott and D. Guttmann, "Dialectics of DecisionMaking in Older Adults,” Human Development, Vol. 21, No. 3, 1978, pp. 190-200. doi:10.1159/000271582

[44] D. Kramer and D. Woodruff, "Relativistic and Dialectical Thought in Three Adult Age Groups," Human Development, Vol. 29, No. 5, 1986, pp. 280-290. doi:10.1159/000273064

[45] D. Moshmann, "Exogenous, Endogenous and Dialectical Constructivism,” Developmental Review, Vol. 2, No. 4, 1982, pp. 371-384. doi:10.1016/0273-2297(82)90019-3

[46] R. J. Sternberg "Wisdom. Its Nature, Origins and Development," Cambridge University Press, New York, 1990. doi:10.1017/CBO9781139173704

[47] A. Lemieux, G. Boutin, M. Sanchez and J. Riendeau, "Gerontagogy beyond Words: A Reality,” Éditions Nouvelles, Montréal, 2005. 